\title{
SARS-CoV-2 infection as possible downstream disease precipitator in autoantibody-positive insulin-dependent diabetes mellitus: a case report
}

\author{
Riccardo Schiaffini $1^{*}$, Andrea Campana ${ }^{2}$, Annalisa Deodati ${ }^{1}$, Emanuela Peschiaroli², \\ Maria Francesca Lanzillotta ${ }^{3}$ and Alessandra Fierabracci ${ }^{3 *}$
}

\begin{abstract}
Background: SARS-CoV-2 causes lesions, in addition to lung, in endocrine organs such as the pancreas through ACE2 receptor. Recently the relationship between SARS-CoV-2 exposition and the incidence or evolution of clinical autoimmune diabetes has attracted the attention of diabetologists.

Case presentation: We report the analysis of the clinical history of a child diagnosed for insulin-dependent diabetes mellitus (Type 1 diabetes) at the time a paucisymptomatic COVID-19 infection occurred, followed by well-controlled metabolic status. As opposite to previous findings SARS-CoV2 did not cause ketosis and ketoacidosis. Polydipsia was reported a few months and weight loss 4 weeks before SARS-CoV-2 infection suggesting that SARS-CoV-2 could not be the trigger of Type 1 diabetes in this patient.

Conclusions: SARS-CoV-2 in this patient was an unexpected event in the course of disease. We advance the hypothesis that the SARS-CoV-2 infection, even if paucisymptomatic could have acted in the present case report as a hypothetical downstream precipitating factor; whilst the inciting triggering event of the autoimmune disease, as confirmed by the presence of circulating autoantibodies, could have occurred even before, as generally assumed for this category of disorders. The precipitating mechanism could have been the acute interaction between virus and the ACE receptor on the beta cells, at the time that hyperglycemia and glycosuria were ascertained, and HbA1c levels confirmed a metabolic dysregulation over the previous 3 months in absence of ketoacidosis.
\end{abstract}

Keywords: Type 1 diabetes, COVID-19, Disease etiopathogenesis, Management

*Correspondence: riccardo.schiaffini@opbg.net; alessandra.fierabracci@opbg. net

${ }^{1}$ Diabetes and Growth Disorders Unit, Academic Department of Pediatrics, Bambino Gesù Children's Hospital IRCCS, Rome, Italy

${ }^{3}$ Infectivology and Clinical Trials Research Department, Bambino Gesù Children's Hospital IRCCS, Rome, Italy

Full list of author information is available at the end of the article

\section{Background}

The ongoing COVID-19 pandemic is caused by the severe acute respiratory syndrome- coronavirus-2 (SARS-CoV-2) which can lead to severe illness and death [1]. SARS-CoV-2 causes lesions not only in the lungs but also in other organs, including endocrine ones $[1,2]$. Viral tropism in these tissues relies on receptors for the coronavirus spike protein, such as the angiotensin-converting enzyme 2 (ACE2) and the transmembrane serine protease 2 (TMPRSS2) [1]. Indeed SARS-CoV-2 infects original author(s) and the source, provide a link to the Creative Commons licence, and indicate if changes were made. The images or other third party material in this article are included in the article's Creative Commons licence, unless indicated otherwise in a credit line to the material. If material is not included in the article's Creative Commons licence and your intended use is not permitted by statutory regulation or exceeds the permitted use, you will need to obtain permission directly from the copyright holder. To view a copy of this licence, visit http://creativecommons.org/licenses/by/4.0/. The Creative Commons Public Domain Dedication waiver (http://creativeco mmons.org/publicdomain/zero/1.0/) applies to the data made available in this article, unless otherwise stated in a credit line to the data. 
and replicates within the cells of exocrine pancreas and pancreatic islets [2]. SARS-CoV-2 might therefore affect the function of beta cells and their insulin secretion thus contributing to metabolic dysregulation in COVID-19 patients demonstrated by increased hyperglycemia in Type 2 diabetes patients [2] and ketoacidosis occurring in diabetic and non-diabetic individuals [3]. Furthermore, the relationship between ketoacidosis and the onset Type 1 diabetes (T1D), in absence of islet- related autoantibodies (Abs), has been reported [4].

It is hypothesized that SARS-CoV-2, like other viruses or unknown environmental factors, could indeed act as a trigger for the onset of autoimmunity [5]. Some patients have developed Guillain-Barré syndrome or systemic lupus erythematosus, autoimmune haemolytic anaemia, thrombotic thrombocytopenic purpura or thrombocytopenic purpura and Graves' disease after COVID-19 infection [6, 7]. Nevertheless the role of SARS-CoV-2 as trigger factor for autoimmunity needs still to be fully unraveled. We present a case report of a child affected by T1D with a paucisymptomatic COVID-19 infection that offers the opportunity to speculate on the possible mechanism of the viral influence on the disease.

\section{Case presentation}

We present the case of a 12 year old white male patient with height $156 \mathrm{~cm}$ and weight $53.5 \mathrm{~kg}$. He was admitted to our emergency Department with a history of headaches and fever over the past 3 days, responsive to paracetamol and corticosteroid treatment, without the typical chest pain. In the previous 3 months the patient presented polydipsia and experienced a weight loss of $5 \mathrm{~kg}$ in the past 4 weeks. The family history was negative for autoimmune diseases but revealed an aunt on the mother's side with Friedreich ataxia and hypertension. Laboratory testing demonstrated hyperglycemia (>400 $\mathrm{mg} / \mathrm{dl}$, normal range 60-100) with c-peptide level $2.47 \mathrm{ng} / \mathrm{mL}$ (normal range 1.10-4.40) and haemoglobin A1c (HbAlc) of $122 \mathrm{mmol} / \mathrm{mol}$ (>48 decisional level for diabetes diagnosis), without ketoacidosis (ph 7.34, BE -5.8 HCO3 std 19.5). In consideration of the acute onset, the clinical phenotype and the age of the child, T1D was assumed. Human leukocyte antigen (HLA) genotyping revealed that the patient had the predisposing haplotypes DRB1*03*, DQB1*02* and DQA1*05*. Celiac disease haplotype 1 DRB1*03-DQA1*05-DQB1*02 and haplotype 2 DRB1*07-DQA1*0201-DQB1*02 were also detected. Serum diabetes-related glutamic acid decarboxylase isoform 65 (GAD65) Abs and anti-zinc transporter 8 (ZnT8) Abs tested positive, while tyrosine phosphatase-insulinoma-associated antigen (IA2), insulin (AIA), thyroperoxidase (TPO), thyroglobulin (Tg) and
Table 1 Autoantibodiesscreening in the serum of case reports. The Table refers to levels of islet-related, thyroid-related, ATG serum autoantibodies and EMA for Patient 1 and 2

\begin{tabular}{llll}
\hline Reference range & Patient 1 & Patient 2 \\
\hline GAD65-Ab & Negative $<5$ Positive $>5$ & $34\left(\mathrm{U} \mathrm{ml}^{-1}\right)$ & $91\left(\mathrm{U} \mathrm{ml}^{-1}\right)$ \\
IA-2-Ab & Negative $<7.5$ Positive $>7.5$ & $<7.5\left(\mathrm{U} \mathrm{ml}^{-1}\right)$ & $134\left(\mathrm{U} \mathrm{ml}^{-1}\right)$ \\
ZnT8-Ab & Negative $<15$ Positive $>15$ & $642\left(\mathrm{U} \mathrm{ml}^{-1}\right)$ & $<15\left(\mathrm{U} \mathrm{ml}^{-1}\right)$ \\
AIA-Ab & Negative $<10$ Border- & $<10\left(\mathrm{U} \mathrm{ml}^{-1}\right)$ & $\mathrm{NT}$ \\
& line $>7-10$ Positive $>=10$ & & \\
TPO & $<34$ & $<9.0(\mathrm{IU} / \mathrm{mL})$ & $10.9\left(\mathrm{U} \mathrm{ml} l^{-1}\right)$ \\
Tg & $<115 \mathrm{IU} / \mathrm{mL}$ & Negative & Negative \\
EMA IgA & Negative & NT & weakly positive \\
EMA IgG & Negative & NT & NT \\
ATG IgA & Negative $=<20$ weakly & $8.3(\mathrm{CU})$ & $530.9(\mathrm{CU})$ \\
& positive $=20-30$ Posi- & & \\
& tive $=>30$ & & \\
\hline
\end{tabular}

NT not tested

transglutaminase (ATG) Abs were negative (Table 1). At referral, COVID-19 infection was confirmed by molecular analysis of naso-pharyngeal and ocular swabs. Infection by other respiratory viruses, including Adenovirus, influenza A/B, parainfluenza 1-4, syncytial A/B, Metapneumovirus, Coronaviruses OC43, 229E, NL63, Rhinovirus A/B/C, Bocavirus $1 / 2 / 3 / 4$ and Enterovirus, was excluded. He did not present metabolic comorbidities and markers (no hypertension, negative CRP $(0.5 \mathrm{mg} / \mathrm{dl}), \mathrm{HdlC}(25 \mathrm{mg} / \mathrm{dl}), \mathrm{LdlC}(52 \mathrm{mg} / \mathrm{dl})$, triglycerides $(131 \mathrm{mg} / \mathrm{dl})$, normal ALT $(14 \mathrm{U} / \mathrm{L})$, AST $(18 \mathrm{U} / \mathrm{L}), \mathrm{gGT}(7 \mathrm{u} / \mathrm{L})$ and ferritin $(119 \mathrm{ng} / \mathrm{ml})$ levels, no liver steatosis).

Lipase, pancreatic amylase and TSH were normal. There was no evidence of retinopathy, nephropathy or of exocrine pancreas involvement since the patient did not complain of diarrhea, increased stool volume and/ or fatty stools. The patient was promptly administered subcutaneous insulin therapy. Over the course of the following few days, his blood glucose levels stabilized. The patient received an educational programme with guidelines for Type 1 diabetes management and was discharged from the hospital in good conditions after 10 days. Four months from the onset, the patient has a well-controlled metabolic status, with $\mathrm{HbA1c}$ value of $46 \mathrm{mmol} / \mathrm{mol}$, following a classical basal-bolus insulin scheme with Multi-Daily Injections, with a total insulin requirement of $0.5 \mathrm{UI} / \mathrm{kg} / \mathrm{die}$. The patient also began to use a Continuous Glucose Monitoring (CGM) system in order to improve blood glucose monitoring and consequently minimize hypo and hyperglycemic episodes, promoting good glucose control with a Time in the ideal (70-180 mg/dl) glucose Range (TIR) of 92\% (Fig. 1). 


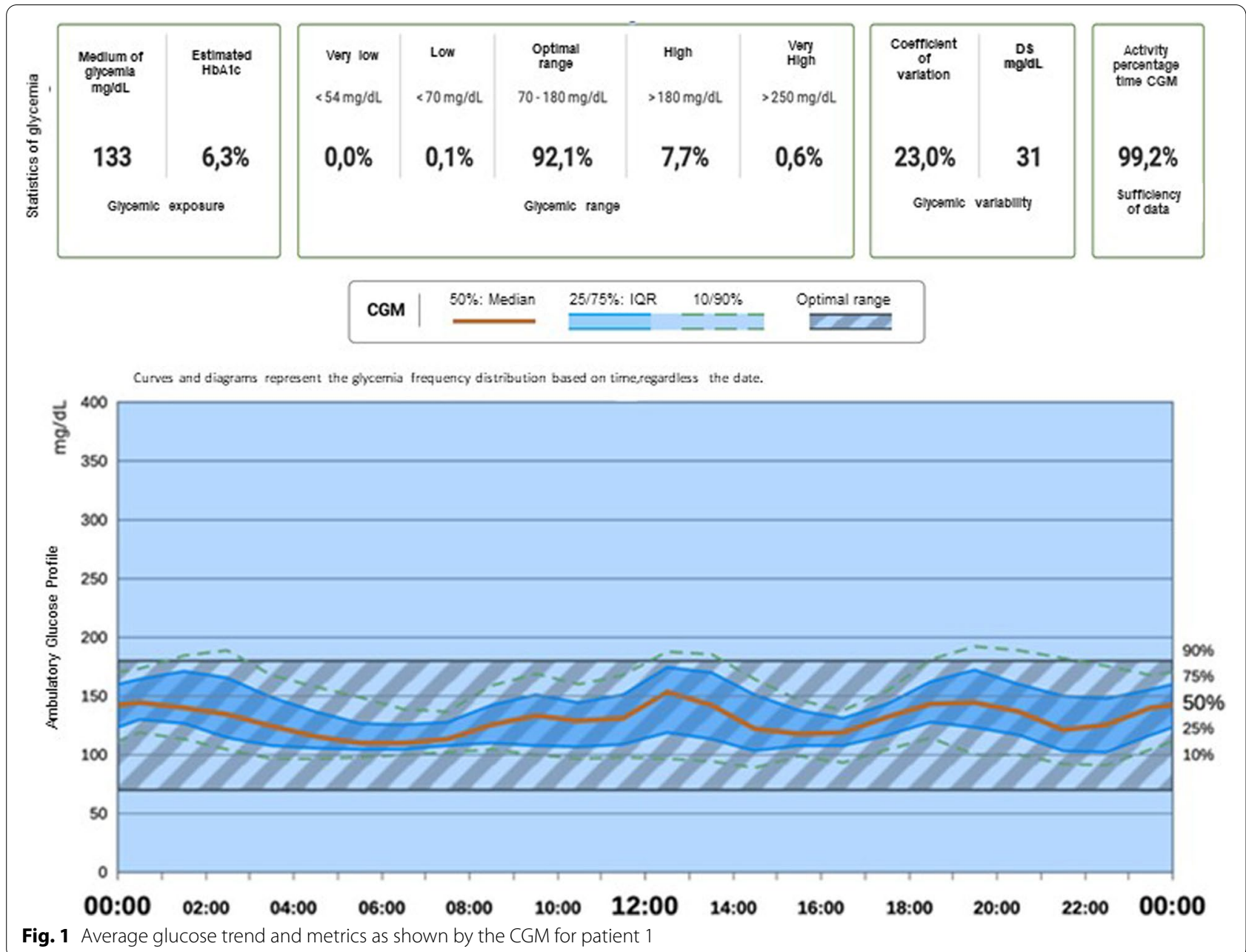

\section{Discussion}

Recently the relationship between SARS-CoV-2 exposition and the incidence or evolution of clinical autoimmune diabetes has attracted the attention of diabetologists based on the hypothesis that diabetes may occur as an acute complication following SARS$\mathrm{CoV}-2$ infection at least in predisposed subjects. Recent investigations suggest that the occurrence of infection in pediatric patients affected by autoimmune diseases does not seem to affect the severity and evolution of the clinical manifestations or the management of the autoimmune disease [8].

The medical history of the patient presented here confirms the recent clinical experiences of pediatric diabetologists, in which SARS-CoV-2 infection does not appear to cause persistent glycemic decompensation in children and adolescents with T1D [8]. Moreover, young patients with disease onset most often have asymptomatic or paucisymptomatic SARS- CoV-2 infection. On a general ground, people with diabetes do not exhibit increased susceptibility to SARS-CoV-2 infection [8].

It is, however, of interest to remark that in the clinical history of the patient reported here the autoimmune process preceded the clinical manifestations of T1D with the symptom of polydipsia, occurring a few months before COVID-19 infection, which was paucisymptomatic. This was also observed in another 8 year old male referred to our Hospital with T1D onset manifested with polyuria and polydipsia in the absence of ketoacidosis associated to celiac disease (Table 1). We confirm that the management of the disease in the patient so far was not significantly affected, being that presently his glycemic status is controlled by the established insulin administration regiment.

Based on previous epidemiological observations, a few months generally lapse between a triggering unknown event, including stress, infectious agents or hormonal perturbations, and the onset of an autoimmune clinical disease [5]. T1D is consequently caused by primary 
mediators, i.e. activated autoreactive $\mathrm{T}$ cells, that invade the pancreatic islets leading to insulitis. During the long-preclinical period that precedes the disease onset and often lasts for years [9], the insulitis would remain innocuous until incited to destruction by any possible secondary event, i.e. the systemic or local reactivity to a viral superantigen [10]. Activated $\mathrm{T}$ cells at this stage expand and destroy insulin-producing beta cells as they react to pancreatic antigens. As a general effect, infectious agents may enhance self-antigen presentation, lead to the involvement of different autoantigens or of different epitopes of the same protein [10].

In light of the foregoing, we advance the hypothesis that the SARS-CoV-2 infection, even if paucisymptomatic could have acted in the present case report as a downstream precipitating factor; whilst the inciting autoimmune triggering event leading to insulitis, as confirmed by the presence of circulating autoantibodies, could have occurred even before, as generally assumed for this category of disorders [5]. SARS-CoV-2 infection could have precipitated the clinical disease onset through the acute interaction between the virus and the ACE receptor on the beta cells leading to massive destruction of their reservoir already compromised by the insulitis previously evoked by the triggering agent. Whilst the putative contribution of the virus on the activation of infiltrating $\mathrm{T}$ cells remains to be demonstrated.

Indeed SARS-CoV-2 infection occurred in our patient at the time that hyperglycemia and glycosuria were ascertained, and HbA1c levels confirmed a metabolic dysregulation over the previous 3 months in absence of ketoacidosis.

\section{Conclusions}

Firstly SARS-CoV-2 infection has effect on T1D clinical onset. Overt disease manifested in this patient at the time that paucisymptomatic viral infection occurred. Secondly, SARS-CoV-2 could not be the trigger of autoimmunity in T1D. Polydipsia was reported a few months and weight loss 4 weeks before SARS-CoV-2 infection. Thirdly, SARS-CoV-2 would have acted as downstream disease precipitator. The direct destruction of beta cells following ACE2 receptor binding is putatively involved. Fourthly, as opposite to previous findings SARS-CoV-2 did not cause ketosis and ketoacidosis.

\footnotetext{
Abbreviations

Abs: Autoantibodies; ACE2: Angiotensin-converting enzyme 2; AIA: Anti-insulin antibodies; ALT: Alanine aminotransferase; AST: Aspartate aminotransferase; ATG: Transglutaminase; CGM: Continuous Glucose Monitoring; COVID-19: Coronavirus disease 19; CRP: C-reactive protein; SARS-CoV-2: Severe acute respiratory syndrome-coronavirus 2;T1D: Type 1 diabetes; GAD65: Glutamic acid decarboxylase isoform 65; Ggt: Gamma-glutamyl transferase; HbA1c: Haemoglobin A1c; HdIC: High-density lipoprotein cholesterol; HLA: Human leukocyte
}

antigen; IA2: Tyrosine phosphatase insulinoma-associated antigen; LdIC: Lowdensity lipoprotein cholesterol; TMPRSS2: Transmembrane serine protease 2; Tg: Thyroglobulin; TIR: Time in the ideal glucose Range; TPO: Thyroperoxidase; TSH: Thyroid- stimulating hormone; ZnT8: Zinc transporter 8.

\section{Acknowledgements}

Not applicable

\section{Authors' contributions}

$\mathrm{RS}, \mathrm{ML}, \mathrm{AF}$ wrote the manuscript. AF, AC and RS reviewed the manuscript. $R S, A D, E P$ conducted the clinical work and analysed data. All authors have approved and declare responsibility for the entire content of the final manuscript.

\section{Funding}

This research did not receive any specific grant from funding agencies in the public, commercial, or not-for-profit sectors.

\section{Availability of data and materials}

Data sharing is not applicable to this article as no datasets were generated or analysed during the current study.

\section{Declarations}

\section{Ethics approval and consent to participate}

All procedures performed in studies involving human participants were in accordance with the ethical standards of the institutional and/or national research committee and with the 1964 Helsinki declaration and its later amendments or comparable ethical standards.

The study was approved by the local Institutional review Board (IRB) of Bambino Gesù Children's Hospital. Informed consent was obtained from both patient's parents.

\section{Consent for publication}

Written informed consent was obtained from both patient's parents for publication of this Case Report and any accompanying clinical data. A copy of the written consent is available for review by the Editor of this Journal.

\section{Competing interests}

The authors declare that they have no competing interests.

\section{Author details}

${ }^{1}$ Diabetes and Growth Disorders Unit, Academic Department of Pediatrics, Bambino Gesù Children's Hospital IRCCS, Rome, Italy. ${ }^{2}$ Multispecialistic Pediatric Unit, Emergency Acceptance and General Pediatrics Department, Bambino Gesù Children's Hospital, Rome, Italy. ${ }^{3}$ Infectivology and Clinical Trials Research Department, Bambino Gesù Children's Hospital IRCCS, Rome, Italy.

Received: 15 July 2021 Accepted: 28 January 2022

Published online: 23 February 2022

\section{References}

1. Fierabracci A, Arena A, Rossi P. COVID-19: A Review on Diagnosis, Treatment, and Prophylaxis. Int JMol Sci. 2020;21:5145. https://doi.org/10. 3390/ijms21145145.

2. TXue Q Li Q Zhang W Lin J Wen L Li et al 2020 Blood glucose levels in elderly subjects with type 2 diabetes during COVID-19 outbreak: a retrospective study in a single center medRxiv https://doi.org/10.1101/2020. 03.31.20048579

3. Li J, Wang X, Chen J, Zuo X, Zhang H, Deng A. COVID-19 infection may cause ketosis and ketoacidosis. Diabetes Obes Metab. 2020;22:1935. https://doi.org/10.1111/dom.14057.

4. Hollstein T, Schulte DM, Schulz J, Glück A, Ziegler AG, Bonifacio E, et al. Autoantibody- negative insulin-dependent diabetes mellitus after SARSCoV-2 infection: a case report. Nat Metab. 2020;2:1021. https://doi.org/10. 1038/s42255-020-00281-8.

5. Fierabracci A. Unravelling the role of infectious agents in the pathogenesis of human autoimmunity: the hypothesis of the retroviral involvement 
revisited. Curr Mol Med. 2009;9:1024. https://doi.org/10.2174/1566524097 89839134.

6. Marchand L, Pecquet M, Luyton C. Type 1 diabetes onset triggered by COVID-19. Acta Diabetol. 2020;57:1265. https://doi.org/10.1007/ s00592-020-01570-0.

7. Ehrenfeld M, Tincani A, Andreoli L, Cattalini M, Greenbaum A, Kanduc D, et al. Covid- 19 and autoimmunity. Autoimmun Rev. 2020;19:102597. https://doi.org/10.1016/j.autrev.2020.102597.

8. Cardona-Hernandez R, Cherubini V, lafusco D, Schiaffini R, Luo X, Maahs DM. Children and youth with diabetes are not at increased risk for hospitalization due to COVID-19. Pediatr Diabetes. 2021;2:202. https://doi.org/ 10.1111/pedi.13158

9. Velluzzi F, Secci G, Sepe V, Klersy C, Shattock M, Foxon R, et al. Prediction of type 1 diabetes in Sardinian schoolchildren using islet cell autoantibodies: 10-year follow-up of the Sardinian schoolchildren type 1 diabetes prediction study. Acta Diabetol. 2016;53:73. https://doi.org/10.1007/ s00592-015-0751-y.

10. Benoist C, Mathis D. Retrovirus as trigger, precipitator or marker? Nature. 1997;388:833

\section{Publisher's Note}

Springer Nature remains neutral with regard to jurisdictional claims in published maps and institutional affiliations.

- fast, convenient online submission

- thorough peer review by experienced researchers in your field

- rapid publication on acceptance

- support for research data, including large and complex data types

- gold Open Access which fosters wider collaboration and increased citations

- maximum visibility for your research: over $100 \mathrm{M}$ website views per year

At BMC, research is always in progress.

Learn more biomedcentral.com/submissions 